\title{
Application of Silicon-Initiated Water Splitting for the Reduction of Organic Substrates.
}

\author{
Ashot Gevorgyan $^{\dagger *}$, Satenik Mkrtchyan ${ }^{\dagger}$, Tatevik Grigoryan ${ }^{\dagger}$, and Viktor O. Iaroshenko ${ }^{\dagger *}$ \\ ${ }^{\dagger}$ Homogeneous Catalysis and Molecular Design Research Group at the Center of Molecular and Macromolecular Studies, \\ Polish Academy of Sciences, Sienkiewicza 112, PL-90-363 Łodź, Poland. \\ * Department of Chemistry and Centre for Theoretical and Computational Chemistry (CTCC), University of Troms $\varnothing, 9037$ \\ Tromsø, Norway.
}

\section{Supporting Information Placeholder}

ABSTRACT: The present work describes the utilization of
water as a donor for hydrogen suitable for the reduction of
several important classes of organic compounds. We have
found that the reductive water splitting can be promoted by
a number of metalloids among which silicon shows the best
efficiency and sustainability. The developed methodologies
were applied for the reduction of nitro compounds, $N$-ox-
ides, sulfoxides, alkenes, alkynes, hydrodehalogenation as
well as for the gram-scale synthesis of several substrates of
industrial importance.

Catalytic hydrogenation is one of the basic transformations of Organic Synthesis that is being used in most of the multistep transformations of industrial importance. ${ }^{1}$ These reactions usually are performed by the use of either hydrogen gas or hydrogen donors ${ }^{2}$ which is widely known as transfer hydrogenation. ${ }^{3}$ The transfer hydrogenation is becoming more popular since it excludes the direct use of highly flammable and gaseous $\mathrm{H}_{2}$. There are a number of classes of compounds which can be used as hydrogen donors ${ }^{2}$ in catalytic transfer hydrogenation reactions ${ }^{3}{ }^{n}$ nevertheless, perhaps the most promising source of hydrogen was and remains water, the most abundant molecule on Earth.

Despite enormous efforts made over the last century the direct use of water as a hydrogen donor in Organic Synthesis remains a challenging and unsolved task. According to the known data the splitting of water can follow the following three pathways: (1) oxidative splitting generating $\mathrm{O}_{2} ;{ }^{4}$ (2) reductive splitting generating $\mathrm{H}_{2} ;, 5,12$ (3) direct splitting into elements $\left(\mathrm{O}_{2}+\mathrm{H}_{2}\right) \cdot{ }^{6}$ Most of the presently known strategies of water splitting are photocatalytic or photoelectrochemical processes. ${ }^{4-6}$ In spite of

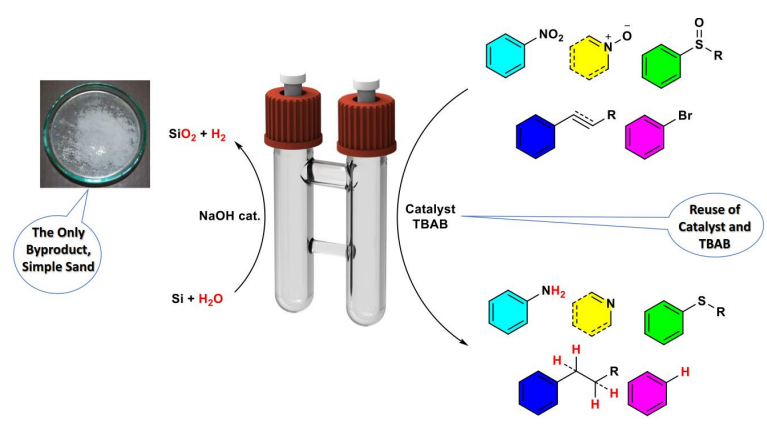

enormous potential, the catalytic water splitting is accompanied with numerous inconveniences and complications (overall efficiency, stability of the catalysts etc.) limiting its practical applications. ${ }^{4-6}$ Subsequently, the development of novel sustainable reductive water splittings used in catalytic hydrogenations remains one of the "holy grails" of modern Organic Synthesis. In this connection, the research made within the last few years indicates that the reductive water splitting can be initiated by various diboron compounds, ${ }^{7}$ phosphines, ${ }^{8}$ DMF/Cu system, ${ }^{9}$ iron powder, ${ }^{10} \mathrm{SmI}_{2}{ }^{11}$ and $\mathrm{Ti}^{\mathrm{III}}$-complexes. ${ }^{12}$

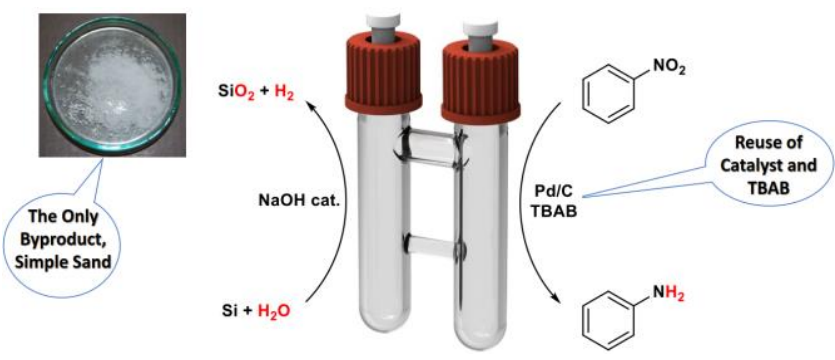

Figure 1. Our strategy on the instance of nitro compounds. 
Continuing our previous research devoted to the selective reductive transformations ${ }^{13}$ we found that the reductive water splitting can be initiated by elemental silicon generating simple sand as the sole byproduct. ${ }^{14}$ Noteworthy, the silicon mediated reductive water splitting can be easily combined with catalytic reductive transformations of a wide range of functional groups (Figure 1). The advantages of our strategy over others are obvious: (1) silicon is the second most abundant element in the earth's crust; (2) except nanosized silicon, all other types of silicon are rather stable under ambient conditions, thus, can be easily transported and used; (3) the reductive water splitting can be conducted without transition metal-based catalysts, light, electricity or substantial heating; (4) the reductive water splitting proceeds by the full conversion of silicon producing simple sand as the only byproduct; (5) the reductive transformations can be performed in "green" solvents using heterogeneous catalysts which can be regenerated and reused. The developed process can be successfully applied for the gram-scale production of several commercial drugs and other substrates of industrial importance. Besides, it should be particularly emphasized that via using $\mathrm{D}_{2} \mathrm{O}$ the deuterium can be completely incorporated into the molecules being reduced.

Initially, the reaction conditions were optimized on the instance of nitrobenzene I (Table 1, see also SI, Table S1). After the screening of a wide range of parameters, it was found that depending on the conditions the reduction of nitrobenzene leads to the formation of aniline 1a, azobenzene $2 \mathbf{a}$ or their mixtures. For instance, heterogeneous $\mathrm{Pd}$ based catalysts $\left(\mathrm{Pd} / \mathrm{C}, \mathrm{Pd} / \mathrm{BaCO}_{3}, \mathrm{Pd} / \mathrm{Al}_{2} \mathrm{O}_{3}\right)$ have shown the best efficiency for the synthesis of aniline (Table 1 , entries 1-3). While $\mathrm{Cu}$-based catalysts leaded to a mixture of aniline and azobenzene (entry 5), the $\mathrm{Fe}(\mathrm{OAc})_{2}$ provided the formation of azobenzene as the only product (entry 6). In addition, it should be mentioned that other Pd- or Fe-based salts/complexes and especially other transition metal-based catalysts were fare less effective.

Table 1. Reaction Optimization. ${ }^{\mathrm{a}}$

\begin{tabular}{|c|c|c|c|c|c|c|}
\hline \multirow[b]{2}{*}{ Entry } & \multicolumn{2}{|c|}{$\begin{array}{c}\text { Si powder } \\
-325 \mathrm{mesh}, \\
\text { Catalyst }(\mathrm{X} \mathrm{mol} \%) \\
\text { Base }(\mathrm{X} \mathrm{mol} \%), \\
\text { Additive }(4 \text { equiv. }), \\
\mathrm{H}_{2} \mathrm{O},{ }^{\circ} \mathrm{C}, \mathrm{h}\end{array}$} & $1 a$ & \multicolumn{3}{|c|}{$2 a$} \\
\hline & $\begin{array}{l}\text { Catalyst } \\
(\mathrm{mol} \%)\end{array}$ & $\begin{array}{c}\text { Base } \\
(\mathrm{mol} \%)\end{array}$ & Additive & ${ }^{\circ} \mathrm{C}$ & $\mathrm{h}$ & $\begin{array}{c}\text { Yield (\%) } \\
\mathbf{1 a} / \mathbf{2 a}^{\mathbf{b}}\end{array}$ \\
\hline 1 & $\mathrm{Pd} / \mathrm{C}(2)$ & $\mathrm{NaOH}(20)$ & TBAB & 100 & 12 & $98 / 0$ \\
\hline 2 & $\mathrm{Pd} / \mathrm{BaCO}_{3}(2)$ & $\mathrm{NaOH}(20)$ & TBAB & 100 & 12 & $95 / 0$ \\
\hline 3 & $\mathrm{Pd} / \mathrm{Al}_{2} \mathrm{O}_{3}(2)$ & $\mathrm{NaOH}(20)$ & TBAB & 100 & 12 & $96 / 0$ \\
\hline 4 & $\mathrm{Pd}(\mathrm{OAc})_{2}(2)$ & $\mathrm{NaOH}(20)$ & TBAB & 100 & 12 & $88 / 0$ \\
\hline 5 & $\mathrm{Cu}(\mathrm{OAc})_{2}(20)$ & $\mathrm{NaOH}(20)$ & TBAB & 100 & 24 & $18 / 46$ \\
\hline 6 & $\mathrm{Fe}(\mathrm{OAc})_{2}(20)$ & $\operatorname{NaOH}(20)$ & TBAB & 100 & 24 & $0 / 89(82)^{c}$ \\
\hline 7 & $\mathrm{Pd} / \mathrm{C}(2)$ & $\mathrm{NaOH}(20)$ & ТВАВ & 100 & 6 & $98(95)^{c} / 0$ \\
\hline 8 & $\mathrm{Pd} / \mathrm{C}(2)$ & $\mathrm{KOH}(20)$ & TBAB & 100 & 6 & $96 / 0$ \\
\hline 9 & $\mathrm{Pd} / \mathrm{C}(2)$ & $\mathrm{KO}^{t} \mathrm{Bu}(20)$ & TBAB & 100 & 6 & $98 / 0$ \\
\hline
\end{tabular}

$\begin{array}{llccccc}10 & \mathrm{Pd} / \mathrm{C}(2) & \mathrm{CsF}(400) & \mathrm{TBAB} & 100 & 6 & 98 / 0 \\ 11 & \mathrm{Pd} / \mathrm{C}(2) & \mathrm{KF}(400) & \mathrm{TBAB} & 100 & 6 & 70 / 0 \\ 12 & \mathrm{Pd} / \mathrm{C}(2) & \mathrm{CsF}(20) & \mathrm{TBAB} & 100 & 6 & 13 / 0 \\ 13 & \mathrm{Pd} / \mathrm{C}(2) & \mathrm{NaOH}(20) & \mathrm{BMIMCl} & 70 & 6 & 98 / 0 \\ \mathbf{1 4} & \mathbf{P d} / \mathbf{C}(\mathbf{2}) & \mathbf{N a O H}(\mathbf{2 0}) & \mathbf{B M I M P F}_{\mathbf{6}} & \mathbf{2 0} & \mathbf{7 2} & \mathbf{8 6 ( 8 2 )} / \mathbf{0}\end{array}$

${ }^{a}$ Reaction conditions: I ( $\left.0.3 \mathrm{mmol}\right)$, Si powder (5 equiv.), base (20-400 mol\%), additive (4 equiv.), catalyst (2-20 mol\%), $20-100^{\circ} \mathrm{C}, 6-72 \mathrm{~h} .{ }^{\mathrm{b}} \mathrm{GC}-$ yield. ${ }^{\mathrm{c}}$ Isolated yield.

The following crucial component of the reaction was the base, which is required for the activation of silicon. Particularly, screening of various bases showed that the silicon mediated water splitting occurred effectively only in the presence of alkali hydroxides, alkoxides and fluorides. While hydroxides and alkoxides are able to catalyze this transformation (entries 1-9), the fluorides need to be used in stoichiometric quantities (entries 10-12). Next, we examined the influence of various ammonium salts on the outcome of the reaction. Noteworthy, most of the ammonium salts are considered as "green" reagents and/or solvents. ${ }^{15}$ In particular, the overall duration of the reaction and the temperature were directly dependent on the ammonium salt being used. For instance, when using TBAB we needed to increase the reaction temperature up to $100^{\circ} \mathrm{C}$ (melting point of TBAB), whereas in the cases of $\mathrm{BMIMCl}$ and $\mathrm{BMIMPF}_{6}$ the reaction went at $70^{\circ} \mathrm{C}$ and room temperature respectively (entries 13, 14). Even though in case of $\mathrm{BMIMPF}_{6}$ for the full conversion of starting material the reaction time needed to be extended up to $72 \mathrm{~h}$ (entry 14). In addition, it should be mentioned that the Fe-catalyzed synthesis of azobenzene despite the prolonged reaction time was not effective at room temperature. In summary, the best conditions for the synthesis of aniline were found to be nitrobenzene (1 equiv.), $\mathrm{Si}$ (5 equiv.), $\mathrm{NaOH}$ (20 mol\%), TBAB/ $\mathrm{BMIMPF}_{6}$ (4 equiv.), $\mathrm{Pd} / \mathrm{C}(2 \mathrm{~mol} \%), 100^{\circ} \mathrm{C} / 20^{\circ} \mathrm{C}, 6 / 72 \mathrm{~h}$ (entries 7,14$)$. Optimal conditions for the preparation of azobenzene are nitrobenzene (1 equiv.), Si (5 equiv.), $\mathrm{NaOH} \mathrm{(20} \mathrm{mol \% ),}$ TBAB (4 equiv.), $\mathrm{Fe}(\mathrm{OAc})_{2}(20 \mathrm{~mol} \%), 100^{\circ} \mathrm{C}, 24 \mathrm{~h}$ (entry 6 ). The absence of any of the components of the reactions decreased the yields of the products dramatically. For more details, see Table $\mathrm{S} 1$ in supplementary information.

Table 2. Screening of Reducing Agents. ${ }^{\text {a,b }}$

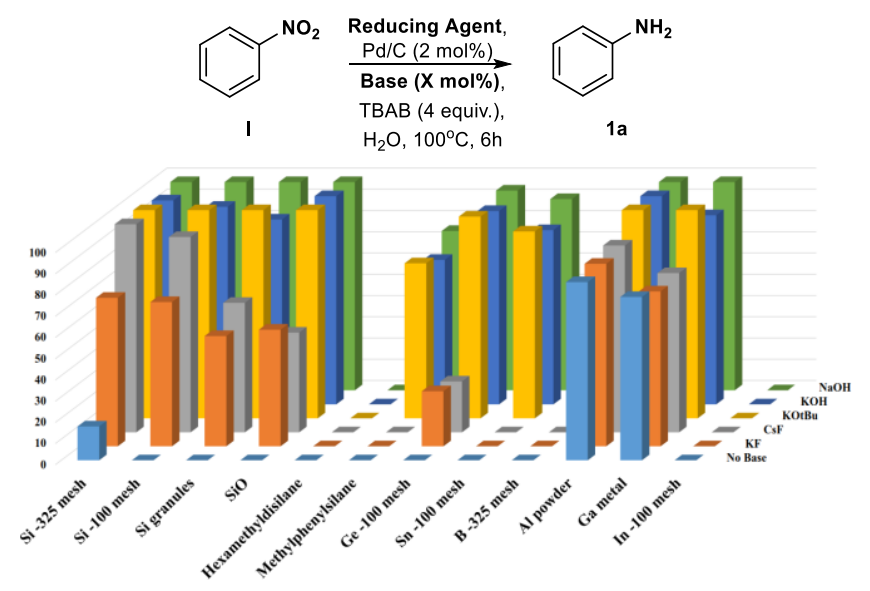


a Reaction conditions: I ( $0.3 \mathrm{mmol})$, reducing agent (5 equiv.), base (20-400 mol\%), TBAB (4 equiv.), Pd/C ( $2 \mathrm{~mol} \%), 100^{\circ} \mathrm{C}, 6 \mathrm{~h} .{ }^{\mathrm{b}} \mathrm{GC}$-yield.

Further, we examined the range and efficiency of metalloids and related chemicals as reducing agents (Table 2). By screening of silicons of various sizes, we concluded that the size matters only when the used bases are fluorides. In addition, we noticed that the silicon powder of -325 mesh slowly reacts with the hot water to some extent even in the absence of bases; however, in this case the conversion of silicon was not completed even at prolonged periods. The amount of used bases has direct influence on the speed of the conversion of silicon to silicon dioxide. For instance, the full conversion of silicon powder of -325 mesh at $80^{\circ} \mathrm{C}$ using $20 \mathrm{~mol} \%$ of $\mathrm{NaOH}$ takes about $6 \mathrm{~h}$. For the temperatures lower than this the full conversion requires either more base or longer reaction time. Among other Si-based reductants we got a quite positive results when using $\mathrm{Si}$ (II) oxide which can be one of possible intermediates of reduction with silicon. While screening of other metalloids of groups 13 and 14 we have found that the reaction fails only with B and In, whereas others are quite effective ( $\mathrm{Tl}$ and $\mathrm{Pb}$ were not examined). Meanwhile $\mathrm{Al}^{16}$ and $\mathrm{Ga}$ are tend to induce the reductive water splitting even without a base (Table 2).

It should be clarified that depending on the substrate being used the reaction should be conducted in different glassware/reactors. Particularly, the reduction of substrates, which do not possess functional groups sensitive under basic conditions, can be conducted either in Ace Pressure Tube or Schlenk flask equipped with an empty balloon. In order to avoid any decomposition all other substrates must be reduced in either COware gas reactor or two interconnected Schlenk flasks equipped with an empty balloon. The reactions performed in Schlenk flasks equipped with an empty balloon took longer (72h) since in these cases the pressure of hydrogen was close to the atmospheric pressure. Besides, in this case the amount of silicon need to be multiplied (see SI).

Following the optimization of reaction conditions, we have concentrated on the examination of the scope and limitations of our strategy. In particular, a wide range of anilines 1a-r can be prepared from corresponding nitro compounds $\mathbf{I}$ in good to excellent yields (Scheme 1, A, Scheme 2). ${ }^{17}$ It should be emphasized that a number of reactive functional groups remain intact when conducting the reaction in COware gas reactor or two interconnected Schlenk flasks (such as $\mathrm{Cl}, \mathrm{Br}, \mathrm{F}$ etc., 1k-n). The optimal conditions are also quite effective for heterocyclic scaffolds 1o,p (Scheme 2). In addition, our conditions can be successfully applied for the reduction of dinitro compounds to corresponding diamines 1q,r; however, in this case the amount silicon and the based need to be doubled. Besides, the silicon powder of -325 mesh can be effectively replaced by Ge powder of -100 mesh (Scheme 2, $\mathbf{1 a}, \mathbf{c}, \mathbf{j}, \mathbf{o})$ or other forms of silicon without any noticeable differences in the yields. Screening of other nitrogen-containing scaffolds indicated that the developed conditions can be used for the reduction of arylhydrazines II to appropriate anilines 1a,d,g from moderate to good yields (Scheme 1, A, Scheme 2). ${ }^{18}$

Further, we have concentrated on the exploration of the scope of Fe-catalyzed synthesis of azobenzenes $\mathbf{2 a - h}$ (Scheme 1, B, Scheme 2) ${ }^{19}$ In this case as well the developed conditions were applicable for a wide range of substituted nitroarenes showing the best efficiency on electron deficient systems $\mathbf{2 b}, \mathbf{e}-\mathbf{h}$. Another crucial finding was that using the present strategy it was possible to couple two different nitroarenes into asymmetrically substituted azobenzenes 2e-h (Scheme 2). This intention was possible to achieve by the usage of $1 / 3$ stoichiometry of two different nitroarenes. In this case the only side product was the homocoupling of nitroarene being used in excess.

\section{Scheme 1. Scope of reductive transformations.}

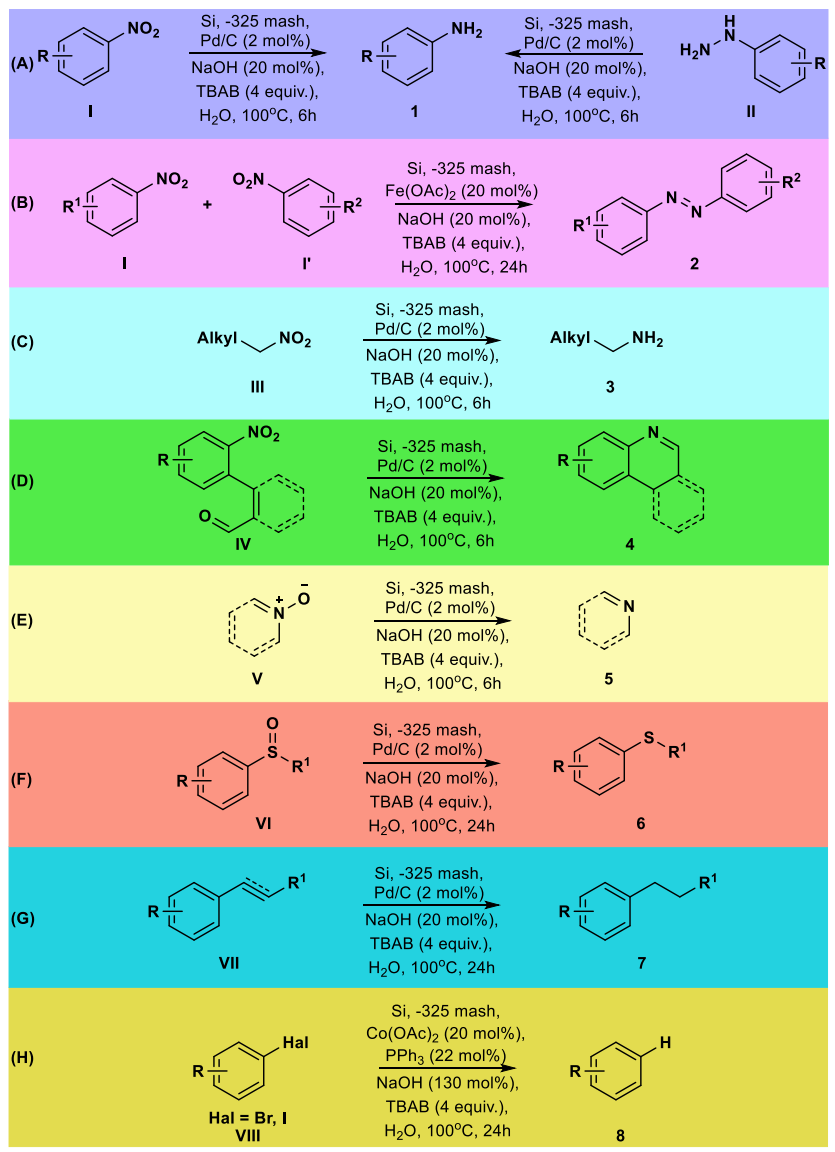

We could also extend the substrate scope towards the reduction of nitroalkanes III (Scheme 1, C, Scheme 2). ${ }^{17}$ It should be particularly emphasized that nitroalkanes did not survived the basic aqueous conditions and in order to succeed we had to use COware gas reactor or two interconnected Schlenk flasks. Doing so it was possible to prepare corresponding aliphatic amines 3a-d in quite reasonable yields (Scheme 2). In addition, the reduction of $\beta$ nitrostyrene leaded to the formation of phenethylamine 
3e. Application of Ge powder was quite efficient also in this case $\mathbf{3 b}$. Besides, the reduction of nitroarenes possessing an adjacent carbonyl functionality IV was accompanied by further cyclization into fused quinolines $\mathbf{4 a}, \mathbf{b}$ (Scheme 1, D, Scheme 2). ${ }^{13}$
Among other related systems, our conditions turned to be quite successful for the reduction of $N$-oxides $\mathbf{V}^{20}$ and sulfoxides VI ${ }^{21}$ (Scheme 1, E, F, Scheme 2). As a result of Pd-catalyzed reduction $N$-oxides were transformed to corresponding heterocycles 5a-d or $N, N$-disubstituted

Scheme 2. Scope of the products and gram-scale production of substrates of industrial importance.

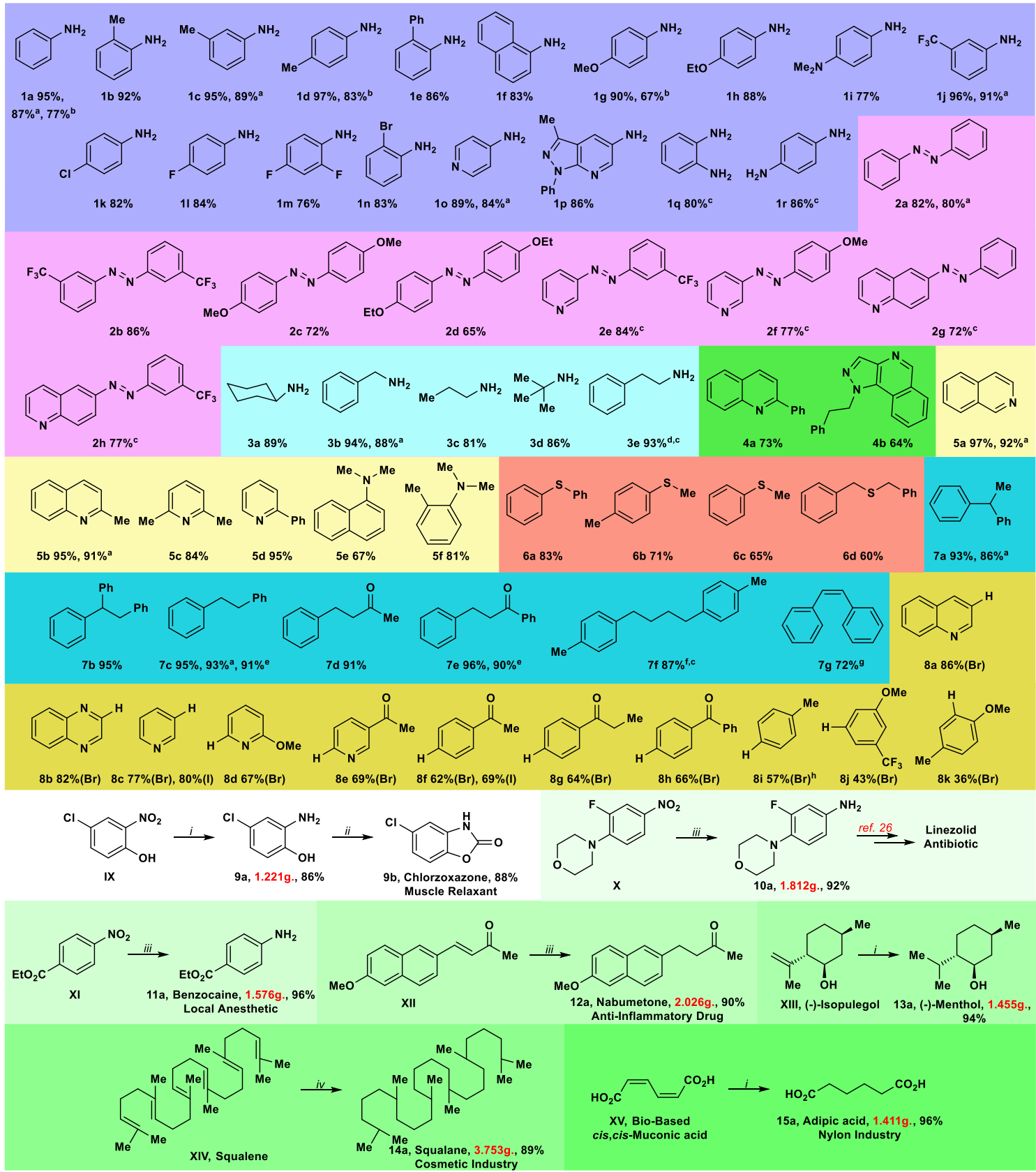

${ }^{a}$ The reductive water splitting was conducted by the use of Ge (5 equiv.). ${ }^{b}$ Yields of the reduction of corresponding hydrazines. ${ }^{\mathrm{c}}$ The amount of silicon and base was doubled. ${ }^{\mathrm{d}} \mathbf{3 e}$ was prepared by the reduction of $\beta$-nitrostyrene. ${ }^{\mathrm{e}}$ Yields of the reduction of corresponding acetylenes. ${ }^{\mathrm{f}}$ Yield of the reduction of corresponding diacetylene. ${ }^{\mathrm{g}}$ The reduction of corresponding acetylene was performed using Lindlar catalyst, see also SI, Table S2. ${ }^{\text {h }}$ GC-yield. $i$ Starting material (10 mmol), Si powder (10 equiv.), $\mathrm{NaOH}(20 \mathrm{~mol} \%)$, EtOH ( $8 \mathrm{~mL}), \mathrm{Pd} / \mathrm{C}(2 \mathrm{~mol} \%), 20^{\circ} \mathrm{C}$, 72h. ii 9a (1 mmol), CDI (1.2 equiv.), DMF (4 mL), $80^{\circ} \mathrm{C}, 5 \mathrm{~h}$. iii Starting material (10 mmol), Si powder (10 equiv.), $\mathrm{NaOH}(20 \mathrm{~mol} \%), \mathrm{TBAB}$ (4 equiv.), $\mathrm{Pd} / \mathrm{C}(2 \mathrm{~mol} \%), 100^{\circ} \mathrm{C}, 72 \mathrm{~h} . i v$ Squalene (10 mmol), Si powder (15 equiv.), $\mathrm{NaOH}(60 \mathrm{~mol} \%), \mathrm{TBAB}(8 \mathrm{equiv}),. \mathrm{Pd} / \mathrm{C}(6$ $\operatorname{mol} \%), 100^{\circ} \mathrm{C}, 144 \mathrm{~h}$.

anilines $\mathbf{5 e , f}$, while sulfoxides turned into appropriate sulfides 6a-d (Scheme 2). In most of the cases the reduction of $N$-oxides proceeded almost quantitatively, whereas the yields of sulfides were moderate. Besides, in order to increase the conversion of sulfoxide the reaction time needed to be extended up to $24 \mathrm{~h}$. In these cases also the $\mathrm{Si}$ can be successfully replaced by Ge $\mathbf{5 a}, \mathbf{b}$.

The developed strategy was efficient not only for the reductions accompanied by deoxygenation but also for 
the hydrogenation of unsaturated double and/or triple bonds VII (Scheme 1, G, Scheme 2). ${ }^{22}$ First we have noticed this during the reduction of $\beta$-nitrostyrene that was followed by simultaneous reduction of both nitro group and the double bond 3e. The main alteration in the typical conditions was the duration of the reaction; thus, the conversion of starting olefins and acetylenes was not complete when the reactions were conducted less than $24 \mathrm{~h}$. Overall, under these conditions the hydrogenation of both olefins 7a-e and acetylenes 7c,e,f underwent smoothly resulting in appropriate saturated systems in excellent yields (Scheme 2). The replacement of Si by Ge can also be accomplished for this reductive transformation 7a,c. In addition, using poisoned Pd-based catalysts we were able to find suitable conditions for the selective semi-hydrogenation of diphenylacetylene into corresponding cis-olefin $\mathbf{7 g}$ that was isolated in $72 \%$ yield (see also SI, Table S2). ${ }^{23}$ The work devoted to the further optimization is in progress.

The final transformation examined in the frames of present study is hydrodehalogenation of aryl halides VIII (Scheme 1, H, Scheme 2). This is another crucial reductive transformation widely used for the neutralization of commercial halogenated pollutants. ${ }^{24}$ It should be noted that the Pd-based conditions were not effective for this task, since they resulted in a mixture consisting of starting material, corresponding hydrodehalogenation product and biaryl (see SI, Table S3). Fortunately, via screening of a wide range of catalysts and other parameters we have found that this transformation can be effectively catalyzed by $\mathrm{Co}(\mathrm{OAc})_{2} / \mathrm{PPh}_{3}$ system. In addition, it should be mentioned that the amount of the base needed to be increased up to $130 \mathrm{~mol} \%$ in order to neutralize the acid formed during the reaction (see SI, Table S3). Overall, the Co-catalyzed hydrodehalogenation proceeds smoothly with electron-deficient heteroarenes 8a-e and arenes possessing electron-withdrawing groups $\mathbf{8 f}-\mathbf{h}$ whereas electron-rich systems $\mathbf{8 i}, \mathbf{k}$ are far less reactive (Scheme 2). In addition, the best results were observed on hydrodehalogenation of aryl iodides and bromides. Aryl chlorides turned to be quite stable under these conditions. It should be noted that the base has a decisive role in this transformation, which explains why the halogens survive during the reduction of halogenated nitro compounds to corresponding anilines 1k-n that is conducted in the absence of a base. Besides, the reduction of the nitro group occurs rather fast resulting in electron-rich systems, which are quite stable towards hydrodehalogenation. We are currently working on the further optimization of this transformation towards hydrodehalogenation of aryl chlorides.

Following the examination of the scope and limitations of developed transformations, we have concentrated on the practical applications of developed methodologies (Scheme 2). It should be noted that the reductive transformations described below were performed on a multigramscale using two interconnected Schlenk flasks equipped with an empty balloon (for the general setup of these reactions see SI, Figure 1). Thus, the reduction of nitrophenol IX leads to corresponding aniline 9a (86\%) which can be further transformed to Chlorzoxazone (muscle relaxant) in $88 \%$ isolated yield. ${ }^{25}$ In case of the reduction of nitrophenol IX the best yields were observed using ethanol as a solvent. The reduction of nitroarene $\mathbf{X}$ resulted in appropriate aniline 10a (92\%) which is the key intermediate in the synthesis of Linezolid (antibiotic). ${ }^{26} \mathrm{Simi}-$ larly, the reduction of nitroarene XI gives rise to Benzocaine 11a (96\%), one of the most frequently used local anesthetics. ${ }^{27}$

Following the same strategy, a number of other valuable substrates of industrial importance can be prepared from suitably substituted olefins. For instance, Nabumetone 12a (90\%, nonsteroidal anti-inflammatory drug) can be easily synthesized by the reduction of corresponding naphthyl-based olefin XII. ${ }^{28}$ Menthol 13a (94\%, food industry, perfumery) can be prepared by the hydrogenation of Isopulegol XIII, which is the key step in the chemical production of Menthol from Citronellal. ${ }^{29}$ Another important constituent of cosmetic industry is Squalane 14a (89\%) which can be synthesized by the hydrogenation of Squalene XIV derived from the shark liver oil. ${ }^{30}$ Last but not least, one of the key ingredients of $\mathrm{Ny}$ lon industry, Adipic acid 15a (96\%), can be prepared by the reduction of biomass-derived cis,cis-Muconic acid $\mathbf{X V} .{ }^{31}$ For the simplification of the isolation process the hydrogenation of cis,cis-Muconic acid XV was conducted in ethanol.

The major advantage of heterogeneous catalysts over homogeneous catalysts is the possibility of separation and reusability. ${ }^{32}$ The reusability of our system was evaluated on the instance of the reduction of nitrobenzene I (Table 3 , for the general setup of the reaction see SI, Figure 1). After each run, the catalyst $(\mathrm{Pd} / \mathrm{C})$ can be easily separated by simple filtration of the dissolved reaction mixture (in DCM) through a glass-edged frit (4-8 $\mu$ m porosity). Accordingly, the activity of the catalyst remains unchanged within the first two runs, while within third and fourth runs in order to get better conversion of the starting material the duration of the reaction need to be doubled (Table 3). At the fifth run, the activity of the catalyst dropped significantly. Besides, the conversion of nitrobenzene was not complete during fourth and fifth runs; thus, in these cases the separation of the product was possible only by the use of column chromatography. In this connection, $\mathrm{TBAB}$ can be separated from the reaction mixture via extraction using distilled water. The separated TBAB can be used repeatedly without any noticeable drop of activity.

\section{Table 3. Reuse of Catalyst}




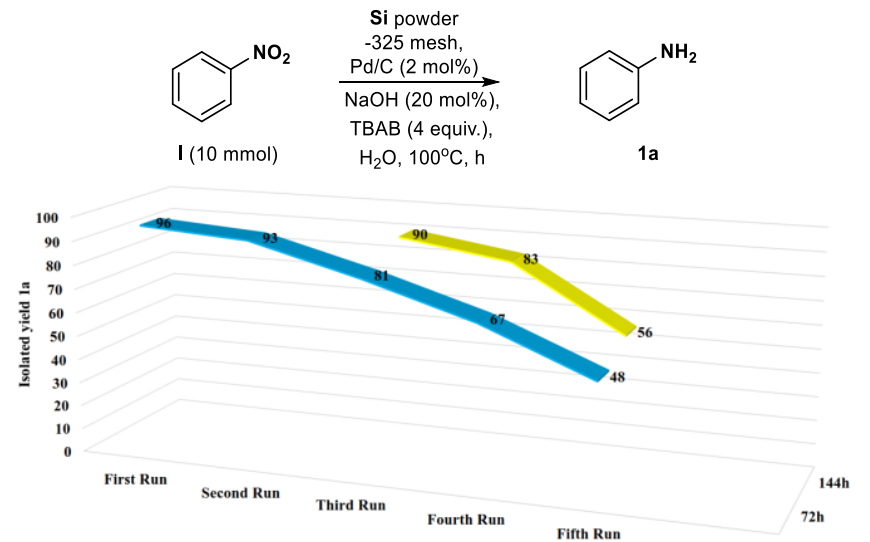

Further studies dealt with the incorporation of deuterium into products of the reduction (Scheme 3 ). This task can be easily achieved via replacement of simple water by deuterated water. Besides, in order to exclude other sources of protium the $\mathrm{NaOH}$ must be replaced by either $\mathrm{KO} t \mathrm{Bu}$ or CsF. Accordingly, the strategy based on the application of $\mathrm{D}_{2} \mathrm{O}$ can be applied for the deuteration of nitro compounds (A), unsaturated hydrocarbons (B) and arenes (C) via deuteriodehalogenation (Scheme 3). It should be mentioned that the deuterated aniline was not separated since this could be accompanied by the loss of deuteriums. In this case the extent of deuteration was evaluated by NMR of the reaction mixture (aniline/TBAB), while the yield of aniline was determined by GC. On the other hand, the deuteration of unsymmetrically substituted olefin revealed uneven distribution of deuterium atoms (Scheme 3, B). This phenomenon can be explained by the overall reversibility of Pd-catalyzed hydrogenation of unsaturated systems. ${ }^{7 b, 33}$ As compared with deuterated aniline the products of the deuteration of olefin and 3-bromoquinoline are quite stable and can be separated by column chromatography. Besides, $\mathrm{CsF}$ was not effective for deuteriodehalogenation of 3-bromoquinoline whereas in the case of commercial $\mathrm{KO} t \mathrm{Bu}$ the extent of deuteration was $85 \%$ (Scheme 3, C).

Scheme 3. Incorporation of Deuterium into Products.
(A)

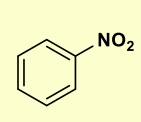

(B)

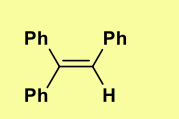

(c)

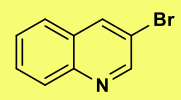

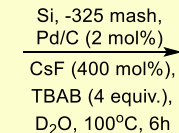

$\mathrm{Si},-325$ mash,

$\underset{\mathrm{Cd} / \mathrm{C}(2 \mathrm{~mol} \%)}{\mathrm{CsF}(400 \mathrm{~mol} \%)}$

TBAB (4 equiv.),

$\mathrm{D}_{2} \mathrm{O}, 100^{\circ} \mathrm{C}, 24 \mathrm{~h}$

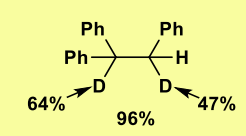

$\mathrm{Si},-325$ mash

$\mathrm{Co}(\mathrm{OAc})_{2}(20 \mathrm{~mol} \%)$

$\frac{\mathrm{PPh}_{3}(22 \mathrm{~mol} \%)}{\mathrm{KOtBu}(130 \mathrm{~mol} \%)}$

KOtBu $(130 \mathrm{~mol} \%)$

$\mathrm{D}_{2} \mathrm{O}, 100^{\circ} \mathrm{C}, 24 \mathrm{~h}$

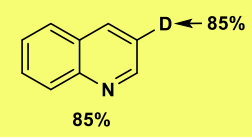

${ }^{\mathrm{a}} \mathrm{GC}$-yield.

Basing on obtained results and known data ${ }^{14,34}$ the possible mechanism of Si-initiated water splitting on the smallest unit of silicon is depicted on Scheme 4. The reaction is initiated by the base which in the first stage of the process attacks empty d orbitals of silicon; thus, cleaving the $\mathrm{Si}$-Si bond (Scheme 4, A). On the next stage of the reaction the silylium anion deprotonates water regenerating the catalyst (Scheme 4, B). On the final stage of the process the base catalyze the dehydrocoupling of $\mathrm{Si}-\mathrm{OH}$ and $\mathrm{H}-\mathrm{Si}$ units which results in the liberation of hydrogen and formation of a siloxane linkage (Scheme 4, C). These processes are running as long as all $\mathrm{Si}-\mathrm{Si}$ bonds are being transformed into Si-O-Si linkages, which is accompanied by the liberation of hydrogen. Noteworthy, the base catalyzed dehydrocoupling of hydrosilanes and alcohols was reported recently. ${ }^{34}$ Besides, during the screening of reducing agents it was found that the combination of methylphenylsilane and water in the presence of catalytic quantities of a base liberates hydrogen; thus, reducing nitrobenzene (Table 2). The IR spectra of the solid product formed by the reaction of silicon and water showed only the asymmetric stretches typical for $\mathrm{Si}-\mathrm{O}-\mathrm{Si}$ linkages of $\mathrm{SiO}_{2}$ (see $\mathrm{SI}$ ).

Scheme 4. Mechanism of Si-Initiated Water Splitting.

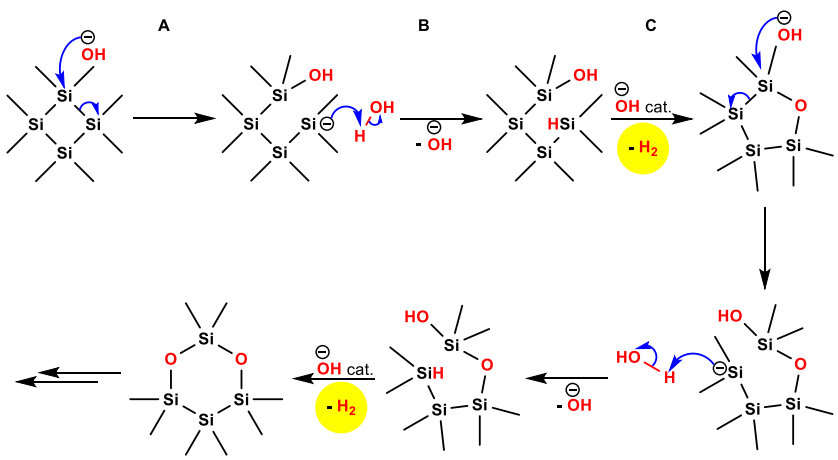

In conclusion, we have developed new methodology of reductive water splitting that can be accompanied by subsequent hydrogenation of a wide spectrum of organic compounds. It was found that the main metalloids of groups 13 and 14 are able to initiate the reductive water splitting. Nevertheless, the best efficiency and sustainability shows silicon that produces simple sand as the main byproduct of the transformation. The developed strategy can be applied for the hydrogenation of nitro compounds, $\mathrm{N}$-oxides, sulfoxides, unsaturated hydrocarbons as well as for the hydrodehalogenation. It should be noted that the catalyst and the solvent could be easily separated and reused. Besides, our methodology is suitable for the gramscale production of several commercial drugs and other products of industrial importance. Finally yet importantly, the replacement of water by $\mathrm{D}_{2} \mathrm{O}$ can be successfully applied for the introduction of deuterium labels into the substrates being reduced.

\section{ASSOCIATED CONTENT}

The Supporting Information is available free of charge on the ACS Publications website at DOI: 
Experimental procedures and characterization data (PDF)

\section{AUTHOR INFORMATION}

\section{Corresponding Author}

*iva108@googlemail.com, viktori@cbmm.lodz.pl.

\section{Notes}

The authors declare no competing financial interests.

\section{ACKNOWLEDGMENT}

Financial support by the Polish National Center of Sciences (NCN) (SONATA 10, Nr. 2015/19/D/ST5/02774) is gratefully acknowledged. We thank Enamine Ltd. Company (Ukraine) for support.

\section{REFERENCES}

(1) (a) Reductions in Organic Synthesis: Recent Advances and Practical Application, A. F. Abdel-Magid (Ed.), ACS symposium series 641, 1996, ISBN: 0-8412-3381-0. (b) Ullmann's Encyclopedia of Industrial Chemistry, Wiley-VCH, Weinheim, 2005, ISBN: 978-3-527-30673-2. (c) The Handbook of Homogeneous Hydrogenation, J. G. de Vries, C. J. Elsevier (Eds.), WILEY-VCH, Weinheim, 2007, ISBN: 978-3-527-31161-3. (d) Modern Reduction Methods, P. G. Andersson, I. J. Munslow (Eds.), WILEY-VCH, Weinheim, 2008, ISBN: 978-3-527-31862-9.

(2) For selected reviews on hydrogen donors and hydrogen production, see: (a) Grochala, W.; Edwards, P. P. Chem. Rev. 2004, 104, 1283 1315. (b) Navarro, R. M.; Pena, M. A.; Fierro, J. L. G. Chem. Rev. 2007, 107, 3952-3991. (c) Esswein, A. J.; Nocera, D. G. Chem. Rev. 2007, 107, 4022-4047. (d) Johnson, T. C.; Morris, D. J.; Wills, M. Chem. Soc. Rev. 2010, 39, 81-88. (e) Mattos, L. V.; Jacobs, G.; Davis, B. H.; Noronha, F. B. Chem. Rev. 2012, 112, 4094-4123. (f) Acar, C.; Dincer, I. Int. J. Hydrog Energy 2014, 39, 1-12. (g) Bhunya, S.; Malakar, T.; Ganguly, G.; Paul, A ACS Catal. 2016, 6, 7907-7934. (h) Heim, L. E.; Konnerth, H.; Prechtl, M. H. G. Green Chem. 2017, 19, 2347-2355. (i) Crabtree, R. H. Chem. Rev. 2017, 117, 9228-9246. (j) Preuster, P.; Papp, C.; Wasserscheid, P. Acc. Chem. Res. 2017, 50, 74-85.

(3) For a comprehensive review on transfer hydrogenation, see: Wang, D.; Astruc, D. Chem. Rev. 2015, 115, 6621-6686.

(4) For selected reviews on water oxidation, see: (a) Karkas, M. D.; Verho, O.; Johnston, E. V.; Akermark, B. Chem. Rev. 2014, 114, 11863 12001. (b) Blakemore, J. D.; Crabtree, R. H.; Brudvig, G. W. Chem. Rev. 2015, 115, 12974-13005. (c) Hunter, B. M.; Gray, H. B.; Müller, A. M. Chem. Rev. 2016, 116, 14120-14136. (d) Suen, N.-T.; Hung, S.-F.; Quan, Q.; Zhang, N.; Xu, Y.-J.; Chen, H. M. Chem. Soc. Rev. 2017, 46, 337-365. (e) Spcri, C.; Kwan, J. T. H.; Bonakdarpour, A.; Wilkinson, D. P.; Strasser, P. Angew. Chem. Int. Ed. 2017, 56, 5994-6021.

(5) For selected reviews on hydrogen evolution, see: (a) Thoi, V. S.; Sun, Y.; Long, J. R.; Chang, C. J. Chem. Soc. Rev. 2013, 42, 2388-2400. (b) Morales-Guio, C. G.; Stern, L.-A.; Hu, X. Chem. Soc. Rev. 2014, 43, 65556569. (c) Zou, X.; Zhang, Y. Chem. Soc. Rev. 2015, 44, 5148-5180. (d) Elgrishi, N.; McCarthy, B. D.; Rountree, E. S.; Dempsey, J. L. ACS Catal. 2016, 6, 3644-3659. (e) Zhang, G.; Lan, Z.-A.; Wang, X. Angew. Chem. Int. Ed. 2016, 55, 15712-15727. (f) Yuan, Y.-J.; Yu, Z.-T.; Chen, D.-Q.; Zou, Z.-G. Chem. Soc. Rev. 2017, 46, 603-631. (g) Hu, Z.; Shen, Z.; Yu, J. C. Green Chem. 2017, 19, 588-613. (h) Mondal, B.; Dey, A. Chem. Commun. 2017, 53, 7707-7715.

(6) For selected reviews on overall water splitting, see: (a) Swierk, J. R.; Mallouk, T. E. Chem. Soc. Rev. 2013, 42, 2357-2387. (b) Osterloh, F. E. Chem. Soc. Rev. 2013, 42, 2294-2320. (c) Ran, J.; Zhang, J.; Yu, J.; Jaroniec, M.; Qiao, S. Z. Chem. Soc. Rev. 2014, 43, 7787-7812. (d) Hisatomi, T.; Kubota, J.; Domen, K. Chem. Soc. Rev. 2014, 43, 7520-7535. (e) Anantharaj, S.; Ede, S. R.; Sakthikumar, K.; Karthick, K.; Mishra, S.; Kundu, S. ACS Catal. 2016, 6, 8069-8097. (f) Zhang, W.; Lai, W.; Cao, R. Chem. Rev. 2017, 117, 3717-3797. (g) Kment, S.; Riboni, F.; Pausova, S.; Wang, L.; Wang, L.; Han, H.; Hubicka, Z.; Krysa, J.; Schmuki, P.; Zboril, R. Chem. Soc. Rev. 2017, 46, 3716-3769. (h) Bae, D.; Seger, B.; Vesborg, P. C. K.; Hansen, O.; Chorkendorff, I. Chem. Soc. Rev. 2017, 46, 1933 1954.
(7) (a) Xia, Y.-T.; Sun, X.-T.; Zhang, L.; Luo, K.; Wu, L. Chem. Eur. J. 2016, 22, 17151-17155. (b) Cummings, S. P.; Le, T.-N.; Fernandez, G. E.; Quiambao, L. G.; Stokes, B. J. J. Am. Chem. Soc. 2016, 138, $6107-$ 6110. (c) Xuan, Q.; Song, Q. Org. Lett. 2016, 18, 4250-4253. (d) Ojha, D. P.; Gadde, K.; Prabhu, K. R. Org. Lett. 2016, 18, 5062-5065. (e) Xuan, Q.; Zhao, C.; Song, Q. Org. Biomol. Chem. 2017, 15, 5140-5144. (f) Wei, Y.; Zhao, C.; Xuan, Q.; Song, Q. Org. Chem. Front. 2017, 4, 2291-2295.

(8) Polezhaev, A. V.; Maciulis, N. A.; Chen, C.-H.; Pink, M.; Lord, R. L.; Caulton, K. G. Chem. Eur. J. 2016, 22, 13985-13998.

(9) Zhang, S.; Ma, Y.; Zhang, H.; Zhou, X.; Chen, X.; Qu, Y. Angew. Chem. Int. Ed. 2017, 56, 8245-8249.

(10) Ma, R.; Liu, A.-H.; Huang, C.-B.; Li, X.-D.; He, L.-N. Green Chem. 2013, 15, 1274-1279.

(11) (a) Kamochi, Y.; Kudo, T. Chem. Lett. 1993, 22, 1495-1498. (b) Szostak, M.; Spain, M.; Eberhart, A. J.; Procter, D. J. J. Org. Chem. 2014, 79, 11988-12003. (c) Szostak, M.; Spain, M.; Eberhart, A. J.; Procter, D. J. J. Am. Chem. Soc. 2014, 136, 2268-2271. (d) Huq, S. R.; Shi, S.; Diao, R.; Szostak, M. J. Org. Chem. 2017, 82, 6528-6540.

(12) (a) Cuerva, J. M.; Campana, A. G.; Justicia, J.; Rosales, A.; Oller-Lopez, J. L.; Robles, R.; Cardenas, D. J.; Bunuel, E.; Oltra, J. E. Angew. Chem. Int. Ed. 2006, 45, 5522-5526. (b) Campana, A. G.; Estevez, R. E.; Fuentes, N.; Robles, R.; Cuerva, J. M.; Bunuel, E.; Cardenas, D.; Oltra, J. E. Org. Lett. 2007, 9, 2195-2198.

(13) (a) Iaroshenko, V. O.; Gevorgyan, A.; Davydova, O.; Villinger, A.; Langer, P. J. Org. Chem. 2014, 79, 2906-2915. (b) Iaroshenko, V. O. Gevorgyan, A.; Mkrtchyan, S.; Grigoryan, T.; Movsisyan, E.; Villinger, A.; Langer, P. ChemCatChem 2015, 7, 316-324. (c) Iaroshenko, V. O.; Gevorgyan, A.; Mkrtchyan, S.; Arakelyan, K.; Grigoryan, T.; Yedoyan, J.; Villinger, A.; Langer, P. J. Org. Chem. 2015, 80, 2103-2119. (d) Gevorgyan, A.; Mkrtchyan, S.; Grigoryan, T.; Iaroshenko, V. O. Org. Chem. Front. 2017, 4, 2437-2444.

(14) The reaction of nanosized silicon with water as well as elementary silicon with hot alkaline solutions is known: (a) Bahruji, H.; Bowker, M.; Davies, P. R. Int. J. Hydrog. Energy 2009, 34, 8504-8510. (b) Litvinenko, S.; Alekseev, S.; Lysenko, V.; Venturello, A.; Geobaldo, F.; Gulina, L.; Kuznetsov, G.; Tolstoy, V.; Skryshevsky, V.; Garrone, E.; Barbier, D. Int. J. Hydrog. Energy 2010, 35, 6773-6778. (c) Zhan, C.; Chu, P. K.; Ren, D.; Xin, Y.; Huo, K.; Zou, Y.; Huang, N. K. Int. J. Hydrog. Energy 2011, 36, 4513-4517. (d) Goller, B.; Kovalev, D.; Sreseli, O. Nanotechnology 2011, 22, 305402, doi:10.1088/0957-4484/22/30/305402. (e) Erogbogbo, F.; Lin, T.; Tucciarone, P. M.; LaJoie, K. M.; Lai, L.; Patki, G. D.; Prasad, P. N.; Swihart, M. T. Nano Lett. 2013, 13, 451-456. (f) Mehta, R. N.; Chakraborty, M.; Parikh, P. A. Int. J. Hydrog. Energy 2014, 39, 80988105. (g) Hu, Y.; Yan, H.; Liu, K.; Cao, H.; Li, W. Int. J. Hydrog. Energy 2015, 40, 8633-8641. (h) Xu, L.; Ashraf, S.; Hu, J.; Edwards, P. P.; Jones, M. O.; Hadzifejzovic, E.; Foord, J. S. Int. J. Hydrog. Energy 2016, 41, 12730-12737. (i) Imamura, K.; Kimura, K.; Fujie, S.; Kobayashi, H. J. Nanopart. Res. 2016, 18:116, DOI 10.1007/s11051-016-3418-x. (j) Kobayashi, Y.; Matsuda, S.; Imamura, K.; Kobayashi, H. J. Nanopart. Res. 2017, 19:176, DOI 10.1007/s11051-017-3873-z.

(15) For selected reviews on catalysis in ionic liquids, see: (a) Welton, T. Chem. Rev. 1999, 99, 2071-2083. (b) Dupont, J.; de Souza, R. F.; Suarez, P. A. Z. Chem. Rev. 2002, 102, 3667-3692. (c) Parvulescu, V. I.; Hardacre, C. Chem. Rev. 2007, 107, 2615-2665. (d) Sledz, P.; Mauduit, M.; Grela, K. Chem. Soc. Rev. 2008, 37, 2433-2442. (e) Haumann, M.; Riisager, A. Chem. Rev. 2008, 108, 1474-1497. (f) Zhang, Q.; Zhang, S.; Deng, Y. Green Chem. 2011, 13, 2619-2637. (g) Santos, C. I. M.; Barata, J. F. B.; Faustino, M. A. F.; Lodeiro, C.; Neves, M. G. P. M. S. RSC Adv. 2013, 3, 19219-19238. (h) Dai, C.; Zhang, J.; Huang, C.; Lei, Z. Chem. Rev. 2017 $117,6929-6983$.

(16) The application of Al-mediated reductive water splitting was reported recently: Schäfer, C.; Ellstrom, C. J.; Cho, H.; Török, B. Green Chem. 2017, 19, 1230-1234.

(17) For selected reviews on the reduction of nitro compounds, see: (a) Tafesh, A. M.; Weiguny, J. Chem. Rev. 1996, 96, 2035-2052. (b) Lara, P.; Philippot, K. Catal. Sci. Technol. 2014, 4, 2445-2465. (c) Serna, P.; Corma, A. ACS Catal. 2015, 5, 7114-7121. (d) Aditya, T.; Pal, A.; Pal, T. Chem. Commun. 2015, 51, 9410-9431. (e) Kadam, H. K.; Tilve, S. G. RSC Adv. 2015, 5, 83391-83407. (f) Orlandi, M.; Brenna, D.; Harms, R.; Jost, S.; Benaglia, M. Org. Process Res. Dev. DOI: 10.1021/acs.oprd.6b00205. (18) For selected papers on the reduction of hydrazines, see: (a) Alonso, F.; Candela, P.; Gomez, C.; Yus, M. Adv. Synth. Catal. 2003, 345, 275-279. (b) Zhang, Y.; Tang, Q.; Luo, M. Org. Biomol. Chem. 2011, 9, 4977-4982. (c) Yuki, M.; Miyake, Y.; Nishibayashi, Y. Organometallics 
2012, 31, 2953-2956. (d) Zhao, D.; Vsquez-Cspedes, S.; Glorius, F. Angew. Chem. Int. Ed. 2015, 54, 1657-1661.

(19) For a comprehensive review on the synthesis of azo compounds, see: Merino, E. Chem. Soc. Rev. 2011, 40, 3835-3853.

(20) For selected papers on the reduction of $N$-oxides, see: (a) Wang, Y.; Espenson, J. H. Org. Lett. 2000, 2, 3525-3526. (b) Jie, Z.; Rammoorty, V.; Fischer, B. J. Org. Chem. 2002, 67, 711-719. (c) Bjorsvik, H.-R.; Gambarotti, C.; Jensen, V. R.; Gonzalez, R. R. J. Org. Chem. 2005, 70, 3218 3224. (d) Kokatla, H. P.; Thomson, P. F.; Bae, S.; Doddi, V. R.; Lakshman, M. K. J. Org. Chem. 2011, 76, 7842-7848. (e) Ma, R.; Liu, A.-H.; Huang, C.-B.; Li, X.-D.; He, L.-N. Green Chem. 2013, 15, 1274-1279. (f) Jeong, J.; Lee, D.; Chang, S. Chem. Commun. 2015, 51, 7035-7038. (g) RubioPresa, R.; Fernandez-Rodriguez, M. A.; Pedrosa, M. R.; Arnaiz, F. J.; Sanz, R. Adv. Synth. Catal. 2017, 359, 1752-1757.

(21) For selected papers on the reduction of sulfoxides, see: (a) Fernandes, A. C.; Fernandes, J. A.; Romao, C. C.; Veiros, L. F.; Calhorda, M. J. Organometallics 2010, 29, 5517-5525. (b) Krackl, S.; Company, A.; Enthaler, S.; Driess, M. ChemCatChem 2011, 3, 1186-1192. (c) Ma, R.; Liu, A.-H.; Huang, C.-B.; Li, X.-D.; He, L.-N. Green Chem. 2013, 15, 1274 1279. (d) Jang, Y.; Kim, K. T.; Jeon, H. B. J. Org. Chem. 2013, 78, 63286331. (e) Mitsudome, T.; Takahashi, Y.; Mizugaki, T.; Jitsukawa, K.; Kaneda, K. Angew. Chem. Int. Ed. 2014, 53, 8348-8351. (f) Touchy, A. S.; Siddiki, S. M. A. H.; Onodera, W.; Kon, K.; Shimizu, K.-i. Green Chem. 2016, 18, 2554-2560.

(22) For selected reviews on the reduction of unsaturated hydrocarbons, see: (a) Cui, X.; Burgess, K. Chem. Rev. 2005, 105, 3272-3296. (b) Wang, D.-S.; Chen, Q.-A.; Lu, S.-M.; Zhou, Y.-G. Chem. Rev. 2012, 112 , 2557-2590. (c) Verendel, J. J.; Pamies, O.; Dieguez, M.; Andersson, P. G. Chem. Rev. 2014, 114, 2130-2169. (d) Zhang, Z.; Butt, N. A.; Zhang, W. Chem. Rev. 2016, 116, 14769-14827.

(23) For a comprehensive review on semi-hydrogenation of acetylenes, see: Oger, C.; Balas, L.; Durand, T.; Galano, J.-M. Chem. Rev. 2013, $113,1313-1350$

(24) For selected reviews on hydrodehalogenation, see: (a) Alonso, F.; Beletskaya, I. P.; Yus, M. Chem. Rev. 2002, 102, 4009-4091. (b) Chaplin, B. P.; Reinhard, M.; Schneider, W. F.; Schüth, C.; Shapley, J. R.; Strathmann, T. J.; Werth, C. J. Environ. Sci. Technol. 2012, 46, 3655-3670. (c) Agarwal, V.; Miles, Z. D.; Winter, J. M.; Eustaquio, A. S.; Gamal, A. A. E.; Moore, B. S. Chem. Rev. 2017, 117, 5619-5674.

(25) For selected papers on the synthesis of Chlorzoxazone, see: (a) Mukhopadhyay, S.; Gandi, G. K.; Chandalia, S. B. Org. Process Res. Dev. 1999, 3, 201-205. (b) Zou, Y.; Wang, Y.; Wang, F.; Luo, M.; Li, Y.; Liu,
W.; Huang, Z.; Zhang, Y.; Guo, W.; Xu, Q.; Lai, Y. Eur. J. Med. Chem. 2017, 138, 199-211.

(26) For selected papers on the synthesis of Linezolid, see: (a) Hoogenraad, M.; van der Linden, J. B.; Smith, A. A. Org. Process Res. Dev 2004, 8, 469-476. (b) Xu, G. Y.; Zhou, Y.; Xu, M. C. Chin. Chem. Lett. 2006, 17, 302-304.

(27) For selected papers on the synthesis of Benzocaine, see: (a) Huang, H.; Wang, X.; Tan, M.; Chen, C.; Zou, X.; Ding, W.; Lu, X. ChemCatChem 2016, 8, 1485-1489. (b) Jensen, R. K.; Thykier, N.; Enevoldsen, M. V.; Lindhardt, A. T. Org. Process Res. Dev. 2017, 21, 370-376.

(28) For selected papers on the synthesis of Nabumetone, see: (a) Prabhakar, C.; Reddy, G. B.; Reddy, C. M.; Nageshwar, D.; Devi, A. S.; Babu, J. M.; Vyas, K.; Sarma, M. R.; Reddy, G. O. Org. Process Res. Dev. 1999, 3, 121-125. (b) Viviano, M.; Glasnov, T. N.; Reichart, B.; Tekautz, G.; Kappe, C. O. Org. Process Res. Dev. 2011, 15, 858-870.

(29) For selected papers on the synthesis of Menthol, see: (a) Plößer, J.; Lucas, M.; Warna, J.; Salmi, T.; Murzin, D. Y.; Claus, P. Org. Process Res. Dev. 2016, 20, 1647-1653. (b) Kalyon, N.; Hofmann, K.; Malter, J.; Lucas, M.; Claus, P.; Albert, B. J. Catal. 2017, 352, 436-441.

(30) For a comprehensive review on the synthesis of Squalane, see: Ciriminna, R.; Pandarus, V.; Beland, F.; Pagliaro, M. Org. Process Res. Dev. 2014, 18, 1110-1115.

(31) For selected papers on hydrogenation of cis,cis-Muconic acid, see: (a) Matthiesen, J. E.; Carraher, J. M.; Vasiliu, M.; Dixon, D. A.; Tessonnier, J.-P. ACS Sustainable Chem. Eng. 2016, 4, 3575-3585. (b) Rorrer, N. A.; Dorgan, J. R.; Vardon, D. R.; Martinez, C. R.; Yang, Y.; Beckham, G. T. ACS Sustainable Chem. Eng. 2016, 4, 6867-6876.

(32) For selected reviews on reusable heterogeneous catalysts, see: (a) Yin, L.; Liebscher, J. Chem. Rev. 2007, 107, 133-173. (b) Lamblin, M.; Nassar-Hardy, L.; Hierso, J.-C.; Fouquet, E.; Felpin, F.-X. Adv. Synth Catal. 2010, 352, 33-79. (c) Molnar, A. Chem. Rev. 2011, 111, 2251-2320. (33) For discussion of the mechanism of hydrogenation of unsaturated hydrocarbons along with appropriate references, see: March's Advanced Organic Chemistry: Reactions, Mechanisms, and Structure, M. B. Smith, 7th Edition, John Wiley \& Sons, 2013, ISBN: 978-0-470-46259-1. See pages 902-912.

(34) The base-catalyzed dehydrocoupling of hydrosilanes with alcohols and water was reported recently: Toutov, A. A.; Betz, K. N.; Haibach, M. C.; Romine, A. M.; Grubbs, R. H. Org. Lett. 2016, 18, 5776-5779. 


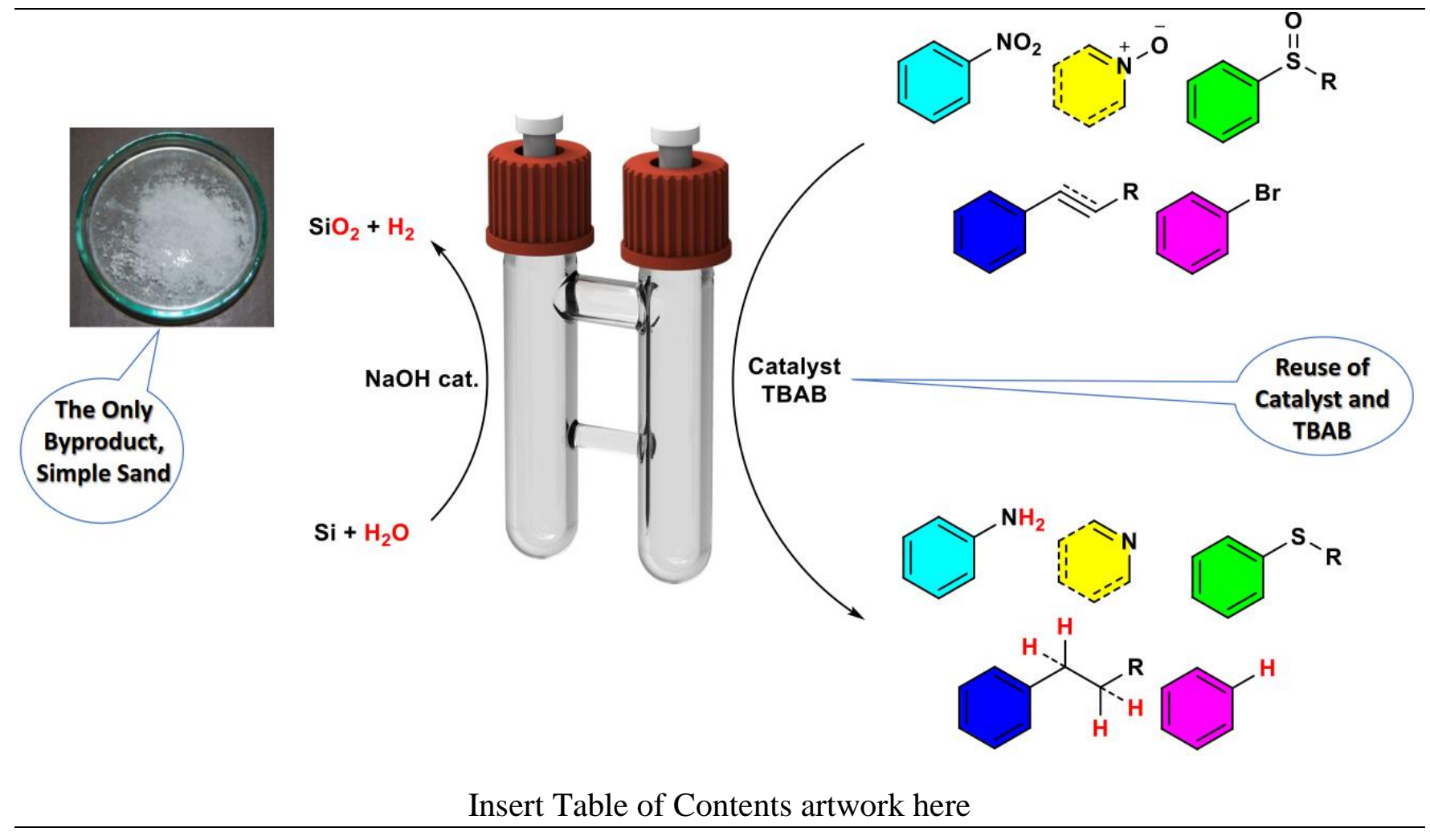

